\title{
Effects of 6 week tennis specific exercises program on service velocity
}

\author{
Erhan KARA ${ }^{1}$, Tolga AKSIT ${ }^{1}$, Mehmet Zeki OZKOL ${ }^{1}$, Turan ISIK ${ }^{2}$ \\ ${ }^{1}$ School of Physical Education and Sport, Ege University, Izmir, Turkey. \\ ${ }^{2}$ School of Physical Education and Sport, Celal Bayar University, Manisa, Turkey. \\ This study was summarized from master thesis and presented as a poster at the 13th International Sports Sciences Congress in Selcuk \\ University (7-9 November 2014). \\ Address correspondence to E. Kara, e-mail: crlop1@hotmail.co.uk
}

\begin{abstract}
Performance in tennis involves various physical, technical/tactical and psychological factors together with a combination of abilities of agility, speed and power. On the other hand today serves have been a most important factor in winning a match. This study examined the effects of 6-week specific exercises program on serve performance and anthropometric characteristics in tennis players. Twenty competitive healthy tennis players were randomly divided into control and training groups. While the training group ( $n=10,22.8 \pm 1.6$ years) performed combined routine tennis training and 3 sessions (each session $45-60$ min) including medicine ball, resistance and balance exercises, the control group ( $n=10,18 \pm 0.0$ years) only performed routine tennis training on court. Serve velocity, body height and weight, body fat ratios were assessed initially and at the end of the six week exercise program. As a result, tennis specific exercise training performed together with the 6 -week tennis exercises program provided further improvement in the serve velocity of tennis players than those in the control group ( $\mathrm{p}<0.05)$. In conclusion, specific exercises are recommended to be performed in order to increase service speed.
\end{abstract}

Keywords: Anthropometric, kinetic chain, service, strength, tennis performance.

\section{INTRODUCTION}

Tennis is a branch of sport which has physiological requirements similar to team sports, can be played on different grounds, includes both aerobic and anaerobic energy metabolisms and in which anaerobic system is considered to be more dominant (9). Achievement in tennis involves various physical, technical/tactical and psychological factors together with a combination of abilities of agility, speed and power (12).

Both upper and lower body strength trainings in tennis players not only improve athletic performance but they also play a role in avoiding injuries (7). Today, serves have been a most important factor in winning a match. Serves at high speeds and correct directions play a key role in winning a tennis match. Lack of sufficient strength training in tennis players may lead to injuries of the shoulder. In addition, a serve is a challenging skill as it involves different movement functions and the lower extremity-upper extremity and trunk movements have to be coordinated with each other. Therefore, many studies have focused on upper and lower extremity movements in serving in tennis $(5,10,13,17)$.

The service ball speed depends on interdependent anthropometric characteristics, biomotor and bio-mechanic factors to act as a complex whole. Among these factors, physical structure, strength, joint movement range of the player and the speed of the racket when serving are considerably important. Moreover, the transfer of strength is provided through the kinetic chain to be produced by the body. The peak racket speed at service has been reported as $100-116 \mathrm{~km} / \mathrm{h}$ and ball speeds as $134-250 \mathrm{~km} / \mathrm{h}(4,5)$.

Producing an effective service movement is achieved through using hip rotation movement, major muscle groups and the coordinated lower extremity muscle groups (hamstring, quadriceps, hip rotator muscles) in a synchronized way. Strength produced at the lower extremity is transferred to the upper extremity and proceeds along the racket together with the ball (22). 
Several studies have shown that tennis specific strength and power trainings performed together with strength trainings increase functional goals and physical performance in a game of tennis $(2,6,11,21,24)$. However, specific strength and power exercises, which affect ball speed particularly at services, must be determined in order to plan trainings more efficiently.

In order to improve performance in tennis, trainers usually focus on the upper extremity and not prefer to creating the accurate kinetic chain for an effective service and performing tennis specific strength exercises. It is only possible to succeed in any branch of sport and to improve performance further by attaining the anthropometric properties projected by that sport. Research has revealed that physical characteristics such as the athletes' anthropometric profiles are among the significant criteria for success in many branches of sport. In the related literature, there are only few studies on service performance and strength training, which particularly trained upper and lower extremities together (11). A service in tennis has a complex structure and includes 8 stages namely the start, release, loading, cocking, acceleration, contact, deceleration, and finish. Training these stages separately in the off-court training is considered to increase service performance.

In this respect, considering the positive effects of tennis specific exercises on performance by simulating the stages of service in tennis; according to our hypothesis, 6-week specific exercises in which upper and lower extremities are worked together in combination with tennis trainings will improve service velocity better than only on-court tennis trainings.

\section{MATERIAL \& METHOD}

\section{Subjects}

Twenty competitive healthy tennis players participated in this study. Subjects were divided into two groups as control $(\mathrm{n}=10$, age $18 \pm 0.0$ years, weight $63.5 \pm 5.4 \mathrm{~kg}$, height $175 \pm 6.5 \mathrm{~cm}$, athlete experience 8.8 years, Body mass index (BMI) 20 $\left.\mathrm{kg} / \mathrm{m}^{2}\right)$ and training $(\mathrm{n}=10$, age $22.8 \pm 1.6$ years, weight $70.4 \pm 7.6 \mathrm{~kg}$, height $175 \pm 5.3 \mathrm{~cm}$, athlete experience 11.2 years, BMI $22 \mathrm{~kg} / \mathrm{m}^{2}$ ).

None of the players in the training group had performed tennis specific exercise programs designed in our study before. The ethics committee, conformed to the recommendations of the
Declaration of Helsinki, approved the study and all subjects signed written informed consent.

\section{Experimental Setup}

Pre and post tests were taken in closed tennis courts at the same time periods $(10.00 \mathrm{am})$. The players were recommended not to do any weight training 48 hours prior to the tests. After taking the players' anthropometric measurements, general and specific warm-up exercises were performed and service velocities were measured with a radar gun afterwards. When the pre-test were completed, the training group were included in a specific exercise program combined with tennis trainings ( 3 days a week) for 6 weeks while the control group did only on-court training 3 days a week. When the training period was completed, tests were repeated on both groups.

\section{Measurements}

Anthropometric Measures: Measurements were performed following the standardized techniques adopted by the International Society for the Advancement of Kinanthropometry (ISAK). Height was measured on a stadiometer (GPM, Seritex, Inc., Carlstadt, New Jersey) to the nearest $0.1 \mathrm{~cm}$, without shoes and weight was recorded on a portable scale (model 707, Seca Corporation, Columbia, Maryland) to the nearest $0.1 \mathrm{~kg}$ without shoes and in minimal clothing. Skinfolds were taken using a calliper (Holtain Ltd, Crymych, UK). All measurements were taken by the same researcher and on the subject's right side. Anthropometric variables included body mass, height and seven skinfolds (triceps, subscapular, axilla, suprailiac, chest, abdominal and thigh). Each site was measured twice (to the nearest $0.2 \mathrm{~mm}$ ) with Harpenden calipers and averaged. With the data obtained, estimated body densitiy was calculated using Jackson and Pollock equation and the data obtained from this equation was put on Siri equation to determine body fat ratio $(19,20,26)$. BMI was calculated as weight/height ${ }^{2}$ where weight was expressed in kilograms and height in meters.

Tennis Serve Velocity: Serve velocity measurements were taken using a radar gun (Sports Radar, Bushnell, USA). The radar device was placed 4 meters behind the athlete by an assistant, was angled towards the direction at which the ball comes out of the racket and eight serve were made in total. The participants were given feedback on velocity in order to attain maximal effort. The fastest $(\mathrm{km} / \mathrm{h})$ of the eight serve made at maximal speed by the players was recorded as the maximal serve. The 
procedures applied for the pre-test were performed for the post-test.

\section{Training Program}

The training group followed the exercise program presented in Table 1 , which was designed as 3 sessions (each session 45-60 min.) a week in addition to on-court trainings for 6 weeks.

\section{Statistical Analysis}

Data analysis was carried out using Statistical Package for the Social Sciences Version 21. The normality distribution of data was checked with using Shapiro-Wilk test and parametric analysis techniques were employed. The differences between pre and post tests were analyzed using Paired Samples $\mathrm{T}$ test and variation ratio of numerical difference between service velocity of the training and control groups were analyzed with Independent Samples $\mathrm{T}$ test. The values obtained are presented as means and standard deviation. Statistical significance was set at $\mathrm{p} \leq 0.05$.

\section{RESULTS}

Differences between service velocities of the training and control groups obtained from pre and post tests are presented in Table 2 . As a result of the tennis specific strength training exercises, the training group improved their service velocities by $23.57 \%(p<0.05)$. In the control group, on the other hand, this change occurred as $5.47 \%(p<0.05)$. In addition, the variation ratio of numerical difference (18.1\%) between service velocities of the training and control groups is statistically significant $(\mathrm{p}<0.05)$.

Differences between body fat ratios of the training and control groups obtained from pre and post tests are given in Table 3 . Body fat ratios of the training group decreased by $2.71 \%$ as a result of the tennis specific exercises $(\mathrm{p}<0.05)$. This decrease was found to be $2.63 \%$ in the control group $(p>0.05)$.

Table 1. Tennis specific exercises (21).

Squatting and standing up with a Olympic bar on shoulders with legs shoulder-width apart. 3 sets 8 reps. $60 \mathrm{~s}$ rest between sets.

$$
\downarrow 90 \text { s rest }
$$

Simulating tennis serve movement with the help of a cable strength device by pulling the cable downwards. $80 \%$ of maximal, 4 sets 8 reps. 60 s rest between sets.

$$
\downarrow 90 \text { s rest }
$$

Standing on balance at quarter squat with hands up on a balance ball. 4 sets $30 \mathrm{~s}, 30 \mathrm{~s}$ rest between sets.

$$
\downarrow 90 \text { s rest }
$$

Simulating tennis service with a $2 \mathrm{~kg}$ medicine ball without using a racket. 2 sets 30 seconds, $40 \mathrm{~s}$ rest between sets.

$\downarrow 60 \mathrm{~s}$ rest

5- Two-arm 90/90 external rotation.

With a cable weight device, standing on feet and moving the cable backwards with external rotation movement from the elbow joint with two arms standing. 3 sets, 12 reps with $75 \%$ of maximal. $40 \mathrm{~s}$ rest between sets.

$$
\downarrow 60 \text { s rest }
$$

Throwing a $2 \mathrm{~kg}$-weight ball backward quickly and swiftly by keeping the 90-degree angle. 2 sets 30 seconds high intensity with $2-\mathrm{kg}$ weight balls. $40 \mathrm{~s}$ rest between sets.

$$
\downarrow 90 \text { s rest }
$$

Throwing a 2kg- weight ball forward quickly and swiftly bay keeping the 90-degree angle. 3 sets 30 seconds with a $2-\mathrm{kg}$ medicine ball, $60 \mathrm{~s}$ rest between sets.

$$
\downarrow 90 \text { s rest }
$$

Maintaining balance on single leg, extending the other leg parallel to the ground, touching the ground with fingertips and coming back to the same position. 3 sets 30 seconds, $60 \mathrm{~s}$ rest between sets.

$$
\downarrow 90 \text { s rest }
$$

Lying back on an exercise ball and doing sit-ups. 2 sets 12 reps, 60s rest between sets.

$$
\downarrow 60 \mathrm{~s} \text { rest }
$$

Throwing forward a medicine ball over the head at maximum power. 3 sets, 10 repetitions, 60 s rest between sets.

\section{$\downarrow 60$ s rest}

Maximum jump with hands up at squat position and then coming down to the same position slowly. 2 sets 6 reps, 90s rest between sets. 
Table 2. Analysis of service speed $(\mathrm{km} / \mathrm{s})$ values of training and control groups.

\begin{tabular}{|c|c|c|c|c|c|}
\hline Group & Pre-test (I) & Post-test (II) & Difference (II-I) & $\Delta \%$ & $\mathrm{P}$ \\
\hline Training & $119.40 \pm 14.74$ & $146.70 \pm 14.48$ & $\uparrow 27.3^{*}$ & $\uparrow 23.57$ & 0.000 \\
\hline Control & $147.10 \pm 14.51$ & $155.00 \pm 14.91$ & $\uparrow 7.9^{\#}$ & $\uparrow 5.47$ & 0.003 \\
\hline
\end{tabular}

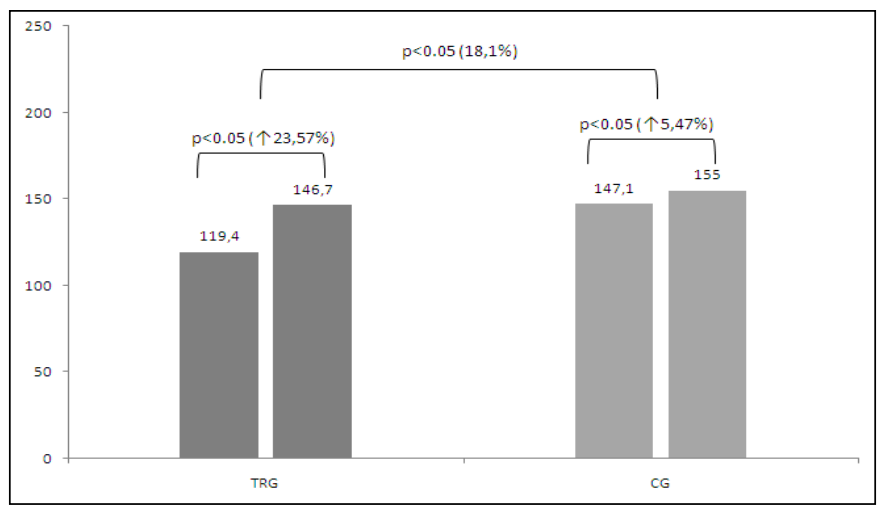

Figure 1. Service speed graph of training and control groups $(\mathrm{km} / \mathrm{h})$.

Table 3. Analysis of body fat ratio values (\%) of training and control groups.

\begin{tabular}{lcccc}
\hline Group & Pre-test (I) & Post-test (II) & Difference (II-I) & P \\
\hline & & & & \\
Training & $13.84 \pm 5.38$ & $11.13 \pm 4.90$ & $\downarrow 2.71^{*}$ & 0.000 \\
Control & $12.91 \pm 7.68$ & $10.28 \pm 4.37$ & $\downarrow 2.63$ & 0.065 \\
& & & & \\
\hline${ }^{*} p<0.05$ & & & &
\end{tabular}

\section{DISCUSSION}

The present study was carried out to examine the effects of short-term tennis specific exercise programs for tennis players on their service speed improvement and body fat ratios. In the related literature, tennis players performance after strength training (core training, elastic tubing and medicine ball exercises) was assessed and no significant increase was observed in the trained group $(8,23)$. A recent study has found a significant increase $(4.9 \%)$ between the trained group and control group in their service speeds of junior tennis players following a 6-week tennis strength program. The training program consisted of upper extremity exercises using elastic tubing. In another study, 25 university tennis players were included in a 4-week isotonic resistance training program performed with theraband elastic tubing and lightweight dumbbells. The study concluded that the use of theraband tubing and lightweight dumbbells could positively contribute to service performance tennis of players at university level (14).

The present study showed that a significant increase was observed in service speeds of the training group following a short-term training program, which occurred as $23.57 \%$ in the training group and $5.57 \%$ in the control group. Considering the percentage change of service speeds in both groups, a statistically significant difference was observed. In the literature, similar studies have used strength-training exercises which are mainly focused on the upper extremity. In our study; however, tennis strength program was designed so as to include both upper and lower extremity exercises and service simulations. In this respect, by using the lower extremities, the produced strength during service movement was also transferred instead of using only the upper extremity muscle groups. For high velocity services, trunk rotation should be maintained, which enables power production. Energy transfer from the lower extremity to the upper extremity through kinetic chain is an assisting factor in power production and medicine balls and core exercises are recommended to perform in power production (8). For tennis players, the speed of transition from the lower extremity to the upper extremity, achieving trunk rotation and the transfer of the strength to the racket and finally to the ball are considerably important. 
Gelen et al. (16) included 46 volunteering male athletes in their study comparing the physical fitness of male tennis players in Turkish first and second leagues. They found that the mean body height of the players in the first league was $183 \mathrm{~cm}$, while it was $176 \mathrm{~cm}$ for the second league players. In a study carried out by Vaverka et al. (29) in 2008, the relationship between body heights of male tennis players that participated in 4 Grand Slam Tournaments and their service ball velocities and significant relations were found between the maximal service ball velocities and body heights of elite tennis players. In the present study, the mean body height of the players is $175 \mathrm{~cm}$, which is similar to the literature. Body height is an important parameter for effective serving in tennis. This allows a tall player to meet the ball at higher points and to make faster serves.

In their study Gelen et al. (16) found the mean body weight of male tennis players in the first and second leagues as $73 \mathrm{~kg}$ for the first league tennis players and $67 \mathrm{~kg}$ for those playing in the second league. Sögüt et al. (28) determined that the mean body weight of tennis players in the junior category A was $42 \mathrm{~kg}$ whereas it was $38 \mathrm{~kg}$ for players in category C. According to a study conducted by Smekal et al. (27), mean body weight of male tennis players was found to be $73 \mathrm{~kg}$. Bahamonde et al. (1) found that the mean body weight of male college tennis players was $77 \mathrm{~kg}$. In our study, on the other hand, mean body weight was determined as $63 \mathrm{~kg}$ for the control group and $70 \mathrm{~kg}$ for the training group. In a study carried out with tennis player of different game levels, mean body weight measurements were found to be $80 \mathrm{~kg}$ for new beginners, $70 \mathrm{~kg}$ for average level tennis players and $73 \mathrm{~kg}$ for elite players (18).

In their study on tennis players, Cohen et al. (6) recorded the body mass index (BMI) as $22 \mathrm{~kg} / \mathrm{m}^{2}$. In their study carried out in order to examine physical fitness and biomechanical factors determining performance in tennis, Gelen et al. (15) found the BMI as $21 \mathrm{~kg} / \mathrm{m}^{2}$. In the study on tennis players conducted by Gelen et al. (16) found that the body mass index of the first league male tennis players was $21 \mathrm{~kg} / \mathrm{m}^{2}$ and the BMI of the second league male tennis players was $21 \mathrm{~kg} / \mathrm{m}^{2}$. In our study, the mean BMI of the training group is $22 \mathrm{~kg} / \mathrm{m}^{2}$ while it is 20 $\mathrm{kg} / \mathrm{m}^{2}$ for the control group.

In our study, body fat ratio in the training group was found as $13.84 \%$ in the pre-test and $11.13 \%$ in the post-test while it was $12.91 \%$ in the pre-test and $10.28 \%$ in the post-test for the control group. As a result of the 6-week tennis specific training, body fat ratio decreased significantly in the training group. Although a decrease was observed in the control group as well, the rate was not statistically significant. Several studies in the literature have revealed the effects of body composition on performance in tennis players. In a study carried out with 18 year-old tennis players, Claudia et al. (3) found the BMI as $21.5 \mathrm{~kg} / \mathrm{m}^{2}$ and the body fat ratio as $14.6 \%$. In a study conducted with junior tennis players, while body fat ratio of players with low ranks was $16 \%$, it was $15.2 \%$ for players that were in the first 12 in the ranking (25).

In conclusion, it was found that the service speed change ratio of the training group was higher after the 6-week specific exercise program. Moreover, the exercise program performed by the training group had positive effects on body composition as well. Therefore, specific exercises are recommended to be performed together with traditional strength training exercises in order to increase service speed.

\section{REFERENCES}

1. Bahamonde R. Changes in angular momentum during the tennis serve. Journal of Sport Sciences, 2000; 18(8): 579-592.

2. Behringer $M$, Neuerburg S, Matthews M, Mester J. Effects of two different resistance training programs on mean tennisserve velocity in adolescents. Pediatric Exercise Science, 2013; 25: 370-384.

3. Claudia RJ, MS. Amancio OMS, Vitalle MSS, Pinheiro MM, Szejnfeld VL. Body composition and nutritional profile of male adolescent tennis players. Journal of Sports Sciences, 2008; 26(11): 1209-1217.

4. Chandler TJ. Conditioning For Tennis: Preventing injury and enchanving performance. In: Lees A. Maynard I, Hughes M. Science and Racket Sports. 2nd ed. London, E\&FN: 1998: 7785 .

5. Chow JW, Park S, Tillman MD. Lower trunk kinematics and muscle activity during different types of tennis serves. Sports Medicine Arthroscopy Rehabilitation Therapy \& Technology, 2009; 1(1): 24.

6. Cohen DB, Mont MA, Campbell KR, Vogelstein BN, Loewy JW. Upper extremity physical factors affecting tennis serve velocity. American Journal of Sports Medicine, 1994; 22: 746750 .

7. Ellenbecker TS, Roetert EP. An isokinetic profile of trunk rotation strength in elite tennis players. Medicine \& Science in Sports \& Exercise, 2004; 36(11): 1959-63.

8. Ellenbecker TS, Roetert EP. Testing isokinetic muscular fatigue of shoulder internal and external rotation in elite junior tennis players. Journal of Orthopedic Sports and Physical Therapy, 1999; 29: 275-281.

9. Elliott B, Dawson B, Pyke F. The energetics of single tennis. Journal of Human Movement Studies, 1985; 11(1): 11-20. 
10. Elliott B, Marsh T, Blanksby B. A three-dimensional cinematographic analysis of the tennis serve. International Journal of Sport Biomechanics, 1986; 2: 260-27.

11. Fernandez FJ, Ellenbecker T, Sanz RD, Ulbricht A, Ferrauti A. Effects of a 6-week junior tennis conditioning program on service velocity. Journal of Sports Science and Medicine, 2013; 12: $232-239$.

12. Fernandez FJ, Sanz RD, Mendez VA. A Review of the activity profile and physiological demands of tennis match play. Strength \& Conditioning Journal, 2009; 31(4): 15-26. DOI 10.1519/SSC.0b013e3181ada1cb.

13. Francis KHW, Jackie HK, Newman ML, Douglas KSN, Joanne WYC, Daniel HKC. Effects of body mass index and full body kinematics on tennis serve speed. Journal of Human Kinetics, 2014; 40: 21-28. DOI: 10.2478/hukin-2014-0003.

14. Frank A, Lott TJ, Duncan J, Slavens G, Davis H. Effects of theraband and lightweight dumbbell training on shoulder rotation torque and serve performance in college tennis players. The American Journal Of Sports Medicine, 1998; 26(4): 510-515

15. Gelen E, Mengütay S, Karahan M. Teniste servis performansını belirleyen fiziksel uygunluk ve biyomekaniksel faktörlerin incelenmesi. International Journal of Human Sciences, 2009; 6(2): 666-682.

16. Gelen E, Saygın Ö, Karahan M, Karacabey K. I. ve II. Ligdeki tenisçilerin fiziksel uygunluk özelliklerinin karşılaştırılması. FÜ Sağlık Bil Dergisi, 2006; 20(2): 119-127.

17. Girard O, Micallef JP, Millet GP. Lower-Limb activity during the power serve in tennis: effects of performance level. Medicine \& Science in Sports \& Exercise, 2005; 37(6): 1021 1029. DOI: 10.1249/01.mss.0000171619.99391.bb.

18. Girard O, Micallef JP, Millet GP. Lower-limb activity during the power serve in tennis: effects of performance level. Medicine \& Science in Sports \& Exercise, 2005; 37(6): 1021-1029.

19. Jackson A, Pollock M,Ward A. Generalized equations for predicting body density of women. Medicine \& Science in Sports \& Exercise,1980; 12: 175-182.
20. Jackson A, Pollock M. Generalized equations for predicting body density of men. British Journal of Nutrition, 1978; 1( 40): 497.

21. Kovacs M, Ellenbecker T. A performance evaluation of the tennis serve: Implications for strength, speed, power, and flexibility training. Strength \& Conditioning Journal, 2011; 33(4): 22-30. DOI: 10.1519/SSC.0b013e318225d59a.

22. Kovacs M, Ellenbecker T. An 8-stage model for evaluating the tennis serve implications for performance enhancement and injury prevention, Sports Health, 2011; 3(6): 504-513.

23. Mont MA, Cohen DB, Campbell KR, Gravare K, Mathur SK. Isokinetic concentric versus eccentric training of shoulder rotators with functional evaluation of performance enhancement in elite tennis players. American Journal of Sports Medicine,1994; 22: 513-517.

24. Reid M, Elliott B, Alderson J. Shoulder joint kinetics of the elite wheelchair tennis serve. British Journal of Sports Medicine, 2007; 41: 737-744.

25. Sánchez CM, Sanz D, Zabala M. Anthropometric characteristics, body composition and somatotype of elite junior tennis players. British Journal of Sports Medicine, 2007;41:793-799. DOI: 10.1136/bjsm.2007.037119.

26. Siri, WE. Body composition from fluid spaces and density. University of California donner laboratory medical and physical report, 1956.

27. Smekal G, Pokan R, von Duvillard SP, Baron R, Tschan H, Bachl N. Comparison of laboratory and "oncourt" endurance testing in tennis. International Journal of Sports Medicine, 2000; 21(4): 242-249.

28. Söğüt M, Müniroğlu RS, Deliceoğlu G. Farklı kategorilerdeki genç erkek tenis oyuncularının antropometrik ve somatotip özelliklerinin incelenmesi. Spormetre Beden Eğitimi ve Spor Bilimleri Dergisi, 2004; 2(4): 155-162.

29. Vaverka F, Cernosek M. Association between body height and serve speed in elite tennis players. Sports Biomechanics, 2013; 12(1): 30-37. DOI.org/10.1080/14763141.2012.670664. 